\title{
Correction \\ Correction: Yang et al. A Learning Control Method of Automated Vehicle Platoon at Straight Path with DDPG-Based PID. Electronics 2021, 10, 2580
}

\author{
Junru Yang ${ }^{1} \mathbb{D}$, Weifeng Peng ${ }^{2}$ and Chuan Sun ${ }^{3,4,5, *}$ \\ 1 Intelligent Transportation Systems Research Center, Wuhan University of Technology, Wuhan 430063, China; \\ yangir@whut.edu.cn \\ 2 Zhongxing Telecommunication Equipment Corporation, Nanjing 210012, China; nspwf1996@163.com \\ 3 School of Electromechanical and Automobile Engineering, Huanggang Normal University, \\ Huanggang 438000, China \\ 4 Department of Civil and Environmental Engineering, The Hong Kong Polytechnic University, \\ Hong Kong, China \\ 5 Suzhou Automotive Research Institute, Tsinghua University, Suzhou 215000, China \\ * Correspondence: sunchuan@tsari.tsinghua.edu.cn; Tel.: +86-151-7146-2316
}

check for updates

Citation: Yang, J.; Peng, W.; Sun, C. Correction: Yang et al. A Learning Control Method of Automated

Vehicle Platoon at Straight Path with DDPG-Based PID. Electronics 2021, 10 2580. Electronics 2022, 11, 617. https://doi.org/10.3390/electronics 11040617

Received: 26 January 2022

Accepted: 28 January 2022

Published: 17 February 2022

Publisher's Note: MDPI stays neutral with regard to jurisdictional claims in published maps and institutional affiliations.

Copyright: (C) 2022 by the authors. Licensee MDPI, Basel, Switzerland. This article is an open access article distributed under the terms and conditions of the Creative Commons Attribution (CC BY) license (https:// creativecommons.org/licenses/by/ $4.0 /)$.

\section{Removal of Authors}

The authors wish to make the following corrections to this paper [1].

D.C., Z.D., L.L., and C.W. were included as authors in the original publication. The corrected Author Contributions Statement appears here. The authors apologize for any inconvenience caused and state that the scientific conclusions are unaffected. The original publication has also been updated.

\section{Removal of Funding}

In the original publication, the funders of the National Natural Science Foundation of China (52172393), the Key Laboratory for Automotive Transaction Safety Enhancement Technology of the Ministry of Communication (Chang'an University), PRC (300102221502), the Key R\&D Program of Hubei Province (2020BAB096) were included. The authors apologize for any inconvenience caused and state that the scientific conclusions are unaffected. The original publication has also been updated.

\section{Additional Affiliations}

In the published publication, there were errors regarding the affiliations for Weifeng Peng, Chuan Sun. The affiliation of Weifeng Peng changed from previous affiliation 1-“Intelligent Transportation Systems Research Center, Wuhan University of Technology, Wuhan 430063, China" to present affiliation 2- "Zhongxing Telecommunication Equipment Corporation, Nanjing 210012, China". One of Chuan Sun's affiliations changed from previous affiliation 2-“Automotive Transportation Safety Assurance Technology Key Laboratory of Transportation Industry, Chang'an University, Xi'an 710064, China" to present affiliation 3-“'School of Electromechanical and Automobile Engineering, Huanggang Normal University, Huanggang 438000, China". The authors apologize for any inconvenience caused and state that the scientific conclusions are unaffected. The original publication has also been updated.

Author Contributions: Conceptualization, J.Y.; methodology, W.P.; software, W.P.; validation, J.Y.; formal analysis, W.P.; investigation, J.Y.; resources, W.P.; data curation, J.Y.; writing—original draft preparation, J.Y.; writing-review and editing, J.Y., W.P. and C.S.; visualization, W.P.; supervision, C.S.; project administration, C.S.; funding acquisition, C.S. All authors have read and agreed to the published version of the manuscript. 
Funding: This work is supported by the National Natural Science Foundation of China (52002215); the Research Project of Hubei Provincial Department of Education (D20212901); the Hubei Science and Technology Project (2021BEC005, 2020BGC026) and the Hong Kong Scholars Program (XJ2021028).

\section{Reference}

1. Yang, J.; Peng, W.; Sun, C. A Learning Control Method of Automated Vehicle Platoon at Straight Path with DDPG-Based PID. Electronics 2021, 10, 2580. [CrossRef] 